Volume: 5 Nomor: 3

1 November 2017

\title{
EFEKTIVITAS MODEL PEMBELAJARAN KOOPERATIF TIPE TPS DAN NHT TERHADAP HASIL BELAJAR MATEMATIKA PADA POKOK BAHASAN BILANGAN BULAT DITINJAU DARI MOTIVASI BELAJAR SISWA KELAS VII SMP NEGERI 1 ILAGA
}

\author{
Retno Wuri Sulistyowati ${ }^{1)}$ dan Irfan Wahyudi ${ }^{2)}$ \\ ${ }^{1)}$ Alumni Program Studi Magister Pendidikan IPA Universitas Cenderawasih \\ ${ }^{2)}$ Dosen Program Studi Magister Pendidikan IPA Universitas Cenderawasih
}

\begin{abstract}
This study aims to determine: (1) NHT type learning model is more effective than TPS type. (2) Students of higher learning motivation are more effective than students with moderate and low motivation, as well as student learning motivation being more effective than students with low motivation. (3) Interaction between learning model of with student learning motivation. (4) Increased learning outcomes using learning model of TPS type and NHT type. Samples taken are class VII A and VII B with the number of students 60 students. The results showed: (1) The learning outcomes using cooperative learning model of NHT type were more effective than those taught by TPS type with the difference of the mean value of 0.16 . (2) The result of analysis of anava analysis showed that Fobs $=115,85$ with significant level $\alpha=0,05$ indicating that the result of student learning having high motivation is more effective than students who have moderate and low motivation, and students who have motivation is more effective than low motivation students. (3) There is an interaction between learning model of TPS type and NHT type learning model in students who have high motivation, moderate or low to mathematics learning result $\mathrm{F}=1.58>\mathrm{F}$ table $=0,215$. (4) There is an increase of learning outcomes by using cooperative learning model of TPS type and NHT type, obtained by n-Gain value of 0.34 in medium category.
\end{abstract}

Keywords: TPS, NHT, Motivation, Mathematics Learning Outcome, Integer

\begin{abstract}
Abstrak. Penelitian ini bertujuan mengetahui: (1) Model pembelajaran tipe NHT lebih efektif daripada tipe TPS. (2) Siswa motivasi belajar tinggi lebih efektif daripada siswa dengan motivasi sedang dan rendah (3) Interaksi antara model pembelajaran dengan motivasi belajar siswa. (4) Peningkatan hasil belajar menggunakan model pembelajaran tipe TPS dan tipe NHT. Sampel yang diambil yaitu kelas VII A dan VII B dengan jumlah siswa 60 siswa. Hasil penelitian menunjukkan: (1) Hasil belajar dengan menggunakan model pembelajaran tipe NHT lebih efektif daripada yang diajar dengan tipe TPS dengan selisih rata-rata nilai 0,16. (2) Hasil uji analisis anava menunjukkan $F_{o b s}=115,85$ dengan taraf signifikan $\alpha=0,05$ yang menunjukkan bahwa hasil belajar siswa yang mempunyai motivasi tinggi lebih efektif daripada siswa dengan motivasi sedang dan rendah, serta siswa yang mempunyai motivasi sedang lebih efektif daripada siswa motivasi rendah. (3) Terdapat interaksi antara model
\end{abstract}


pembelajaran tipe TPS dan model pembelajaran tipe NHT pada siswa yang mempunyai motivasi tinggi, sedang maupun rendah terhadap hasil belajar matematika $F_{o b s}=1,58>F_{\text {tabel }}=0,215$. (4) Terdapat peningkatan hasil belajar dengan menggunakan model pembelajaran tipe TPS dan tipe NHT, diperoleh n-Gain sebesar 0,34 pada kategori sedang.

Kata kunci: TPS, NHT, Motivasi, Hasil Belajar Matematika, Bilangan Bulat.

\section{PENDAHULUAN}

Hasil pengamatan yang penulis lakukan di lapangan pada pembelajaran semester ganjil, khususnya di kelas VII SMP Negeri 1 Ilaga masih banyak siswa yang mendapatkan nilai matematika di bawah 75 (KKM). Pertimbangan penulis menerapkan model pembelajaran kooperatif tipe TPS dan NHT adalah bahwa model pembelajaran kooperatif tipe ini merupakan salah satu model pembelajaran kooperatif yang paling sederhana dalam mengaktifkan siswa, memotivasi siswa untuk lebih kreatif dan inovatif. Ditetapkannya pokok bahasan bilangan bulat karena ditemukan beberapa siswa masih sulit untuk mempelajari dan memahami materi tersebut tanpa melalui model pembelajaran kooperatif tipe TPS dan NHT. Materi yang sedang dipelajari di kelas VII semester I sesuai dengan silabus saat ini berkenaan dengan materi bilangan bulat.

Berdasarkan uraian di atas, peneliti tertarik untuk melakukan penelitian kuantitatif yang berjudul,

"Efektivitas Model Pembelajaran

Kooperatif Tipe TPS dan Model

Pembelajaran Kooperatif Tipe NHT

Terhadap Hasil Belajar Matematika Pada

Pokok Bahasan Bilangan Bulat Ditinjau

Dari Motivasi Belajar Siswa Kelas VII SMP Negeri 1 Ilaga".

\section{METODOLOGI PENELITIAN}

Penelitian ini termasuk penelitian kuantitatif yang dirancang seperti Tabel 1 berikut ini.

Tabel 1. Rancangan Penelitian

\begin{tabular}{|c|c|c|c|}
\hline \multirow{2}{*}{$\begin{array}{c}\text { Model Pembelajaran } \\
\text { Kooperatif }\left(A_{i}\right)\end{array}$} & \multicolumn{3}{|c|}{$\begin{array}{l}\text { Tingkat Motivasi Belajar } \\
\text { siswa }\left(B_{j}\right)\end{array}$} \\
\hline & $\begin{array}{l}\text { Tinggi } \\
\left(b_{1}\right)\end{array}$ & $\begin{array}{c}\text { Sedang } \\
\left(b_{2}\right)\end{array}$ & $\begin{array}{c}\text { Rendah } \\
\left(b_{3}\right)\end{array}$ \\
\hline $\begin{array}{l}\text { TPS } \\
\left(a_{1}\right)\end{array}$ & $a_{l} b_{l}$ & $a_{1} b_{2}$ & $a_{1} b_{3}$ \\
\hline $\begin{array}{l}\text { NHT } \\
\left(a_{2}\right)\end{array}$ & $a_{2} b_{1}$ & $a_{2} b_{2}$ & $a_{2} b_{3}$ \\
\hline
\end{tabular}

\section{Populasi dan Sampel}

Populasi dalam penelitian ini adalah seluruh siswa kelas VII SMP Negeri 1 Ilaga Kabupaten Puncak Papua tahun ajaran 2016/2017, terdiri dari 6 kelas yang berjumlah 180 siswa. Sampel 
yang digunakan adalah dua kelas, yaitu kelas VII A yang berjumlah 30 orang dan kelas VII B yang berjumlah 30 orang.

\section{Instrumen Penelitian}

Instrumen yang digunakan dalam penelitian ini antara lain: observasi, kuisioner atau angket, tes, dan dokumentasi.

\section{HASIL DAN PEMBAHASAN}

Hasil belajar matematika pada pokok bahasan bilangan bulat yang diajar dengan menggunakan model pembelajaran kooperatif tipe NHT lebih efektif daripada tipe TPS.

Hasil deskripsi data yang telah peneliti peroleh dengan diterapkannya model pembelajaran TPS dan NHT, diketahui bahwa tes hasil belajar matematika 15 soal yang dikerjakan oleh 30 siswa yang diajar dengan model pembelajaran kooperatif tipe TPS yang memiliki rata-rata hasil tes 79,17 dan untuk 30 siswa yang diajar dengan menggunakan model pembelajaran kooperatif tipe NHT memiliki rata-rata hasil tes 79,33.

Pada penelitian ini hasil analisis uji hipotesis menunjukkan bahwa $H_{O}$ diterima, ini berarti hasil belajar matematika antara siswa yang diajar dengan menggunakan model pembelajaran kooperatif tipe NHT lebih efektif daripada dengan menggunakan model pembelajaran kooperatif tipe TPS dengan selisih rata-rata nilainya 0,16 . Penelitian ini didukung oleh penelitian terdahulu Murti, Redjeki, dan Utomo (2014) yang menyatakan bahwa, prestasi belajar kognitif siswa pada metode pembelajaran kooperatif NHT lebih tinggi daripada metode pembelajaran kooperatif TPS. Hal ini ditunjukkan dari rerata kelas NHT yaitu 76,36 sedangkan kelas TPS yaitu 60,76.

\section{Hasil belajar matematika pada pokok} bahasan bilangan bulat antara siswa yang mempunyai motivasi belajar tinggi lebih efektif daripada motivasi belajar sedang, dan rendah, serta siswa yang mempunyai motivasi belajar sedang lebih efektif daripada siswa dengan motivasi belajar rendah.

Pada penelitian ini diperoleh hasil dalam skala ordinal nilai terendah 99 dan nilai tertinggi adalah 138. Sedangkan dalam skala interval diperoleh nilai terendah 49,64 dan nilai tertinggi 61,67. Kriteria motivasi rendah terletak pada interval 49,64 sampai 59,13, motivasi sedang terletak pada interval 59,22 sampai 59,73. Sedangkan motivasi 
tinggi terletak pada interval 59,81 sampai 61,67. Penelitian ini didukung oleh Sudarwati, Utami, Martini (2014), bahwa penerapan metode pembelajaran NHT mampu meningkatkan motivasi belajar kelarutan, hasil kali kelarutan dan hasil belajar kelarutan dan hasil kali kelarutan kelas XI IPA 4 SMA Negeri 8 Surakarta.

Adanya interaksi antara model pembelajaran kooperatif tipe TPS dan model pembelajaran kooperatif tipe NHT pada siswa yang mempunyai motivasi belajar tinggi, sedang maupun rendah terhadap hasil belajar matematika pada pokok bahasan bilangan bulat.

Analisis anava diperoleh $J K=50,83$, pada $d k=2, R K=25,417, F_{o b s}$ $=1,58$ lebih besar dari $\mathrm{F}$ tabel yaitu 0,215. Hasil analisis uji hipotesis tersebut menunjukkan bahwa $H_{0}$ diterima, ini berarti ada interaksi antara faktor pembelajaran dengan faktor motivasi siswa. Jika dilihat dari model pembelajaran, siswa yang mempunyai motivasi tinggi lebih efektif daripada siswa yang mempunyai motivasi sedang dan rendah serta siswa yang mempunyai motivasi sedang lebih efektif daripada siswa yang mempunyai motivasi rendah.
Penelitian ini didukung penelitian terdahulu oleh Rahmawati dan Mukminan (2012), bahwa dalam penelitiannya yang berjudul Pengaruh Model Pembelajaran Kooperatif TPS Dan NHT Terhadap Hasil Belajar Sejarah Di SMA Negeri Kabupaten Temanggung terdapat interaksi antara model pembelajaran TPS dan NHT terhadap motivasi belajar peserta didik untuk meningkatkan hasil belajar dalam pembelajaran sejarah, dengan $\mathrm{F}=6,361$ dan $\mathrm{p}=0,014<0,05$.

Adanya peningkatan hasil belajar matematika pada pokok bahasan bilangan bulat dengan menggunakan model pembelajaran kooperatif tipe TPS dan model pembelajaran kooperatif tipe NHT siswa kelas VII SMP Negeri 1 Ilaga.

Mengetahui peningkatan hasil belajar siswa digunakan n-Gain Ternormalisasi. Hasil belajar untuk RPP 1 sampai RPP 3 dapat dilihat pada Tabel 2 berikut ini.

Tabel 2. Rata-rata n Gain Hasil Belajar Siswa TPS dan NHT

\begin{tabular}{|c|c|c|c|c|}
\hline \multirow{2}{*}{ Kelas } & Model & Jumlah & \multicolumn{2}{|c|}{ N Gain } \\
\cline { 4 - 5 } & Pembelajaran & siswa & TPS & NHT \\
\hline VII A & TPS & 30 & 0,22 & \\
\hline VII A & TPS & 30 & 0,34 & \\
\hline
\end{tabular}




\begin{tabular}{|c|c|c|c|c|}
\hline VII A & TPS & 30 & 0,36 & \\
\hline VII B & NHT & 30 & & 0,54 \\
\hline VII B & NHT & 30 & & 0,68 \\
\hline VII B & NHT & 30 & & 0,71 \\
\hline \multicolumn{3}{|c|}{ Jumlah } & 0,99 & 0,71 \\
\hline Rata-rata & 0,31 & 0,64 \\
\hline \multicolumn{3}{|c|}{ Selisih } & \multicolumn{2}{c|}{0,34} \\
\hline
\end{tabular}

Gambar 1. Diagram batang n-Gain

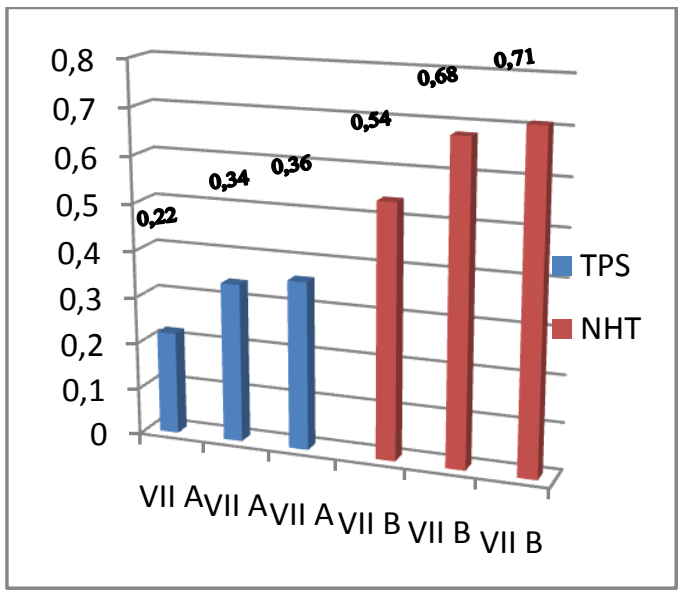

Nilai peningkatan tersebut

disebabkan siswa sebelum diberikan treatmen tidak pernah melakukan suatu proses pembelajaran yang bersifat kooperatif atau pemebelajaranya masih bersifat konvensional namum setelah diberikan model pembelajaran TPS dan NHT siswa lebih aktif dan termotivasi untuk belajar matematika khususnya pada bilangan bulat. Pada penelitian ini ditinjau dari hasil n-Gain, menunjukkan bahwa model pembelajaran NHT lebih efektif dibandingkan dengan model pembelajaran TPS. Hasil di atas didukung oleh Hernovan (2015) yang menyatakan bahwa hasil belajar kelas model NHT lebih tinggi daripada kelas model TPS. Peningkatan tersebut dipengaruhi oleh adanya aktivitas pembelajaran oleh siswa pada kelas model NHT lebih aktif melakukan aktivitas belajar selama pembelajaran daripada kelas model TPS dan dipengaruhi juga ke-mampuan siswa memahami per-masalahan yang ada di dalam soal tes sehingga siswa dapat menjawab soal yang diberikan.

\section{SIMPULAN DAN SARAN}

\section{Simpulan}

Berdasarkan hasil analisa data dan pembahasan penelitian, maka dapat disimpulkan bahwa:

1. Hasil analisis varians yang menunjukkan $F_{o b s}=0,026$ dengan taraf signifikan $\alpha=0,05$. Daerah untuk uji analisis daerah ini adalah $\mathrm{DK}=\left\{F \mid F>F_{0,05 ; 1,58}\right\}=\{F \mid F>$ $0,873\}$ dengan demikian berarti $H_{0}$ ditolak, sehingga dapat disimpulkan bahwa hasil belajar matematika pada pokok bahasan bilangan bulat yang diajar dengan menggunakan model pembelajaran kooperatif tipe NHT lebih efektif daripada dengan menggunakan model pembelajaran kooperatif tipe TPS, karena tipe NHT 
pembagiannya secara heterogen antara siswa motivasi belajar tinggi, sedang, maupun rendah. Berbeda dengan model pembelajaran TPS yang pengelompokannya hanya dengan teman sebangku saja yang belum tentu teman sebangkunya tersebut mempunyai motivasi belajar tinggi, kemungkinan bisa saja sedang atau rendah.

2. Hasil belajar matematika pada pokok bahasan bilangan bulat antara siswa yang mempunyai motivasi belajar tinggi lebih efektif daripada siswa dengan motivasi belajar sedang, dan siswa yang mempunyai motivasi belajar tinggi lebih efektif daripada siswa dengan motivasi belajar rendah, serta siswa yang mempunyai motivasi belajar sedang lebih efektif daripada siswa dengan motivasi belajar rendah. Hal ini dapat ditunjukkan pada hasil uji analisis anava menunjukkan $F_{o b s}=$ 115,85 dengan taraf signifikan $\alpha=$ 0,05. Daerah untuk uji analisis daerah ini adalah $D K=\left\{F \mid F>F_{0,05 ; 2,58}\right\}=$ $\{F \mid F>0,000\}$.

3. Perhitungan anava menunjukkan $F_{o b s}$ $=1,58$ dengan taraf signifikan $\alpha=$ 0,05. Daerah untuk uji analisis daerah ini adalah $D K=\left\{F \mid F>F_{0,05 ; 2,58}\right\}=$
$\{F \mid F>0,215\}$ dengan demikian berarti $H_{0}$ ditolak yang menyatakan adanya interaksi antara model pembelajaran kooperatif tipe TPS dan model pembelajaran kooperatif tipe NHT pada siswa yang mempunyai motivasi belajar tinggi, sedang maupun rendah terhadap hasil belajar matematika pada pokok bahasan bilangan bulat. Jadi penggunaan model pembelajaran dengan motivasi belajar siswa mempunyai pengaruh terhadap hasil belajar matematika siswa.

4. Adanya peningkatan hasil belajar matematika pada pokok bahasan bilangan bulat dengan menggunakan model pembelajaran kooperatif tipe TPS dan tipe NHT, diperoleh rata-rata nilai $n$-Gain pada model pembelajaran tipe TPS sebesar 0,31. Sedangkan model pembelajaraan tipe NHT sebesar 0,64 dan selisih rata-rata kedua model pembelajaran tersebut sebesar 0,34 dikategorikan nilai $\mathrm{n}$ Gain keduanya tergolong dalam kategori sedang.

\section{Saran}

Berdasarkan kesimpulan yang diperoleh dari penelitian yang penulis lakukan di SMP Negeri 1 Ilaga, maka 
penulis memberikan beberapa saran sebagai berikut:

a. Pembelajaran menggunakan model pembelajaran kooperatif tipe NHT dan TPS diharapkan guru mampu mengatur alokasi waktu yang panjang sekitar 3 jam pelajaran agar dalam menyampaikan tujuan pembelajaran dapat berjalan secara efektif, serta daya serap terhadap materi pelajaran dapat maksimal.

b. Salah satu usaha meningkatkan hasil belajar siswa dalam proses belajar mengajar diharapkan seorang guru dapat lebih aktif dan selektif dalam menggunakan metode atau model pembelajaran yang sesuai dengan kondisi siswa dan materi pelajaran, salah satunya dengan menerapkan model pembelajaran kooperatif tipe TPS dan NHT.

c. Modul dan alat-alat peraga matematika sangat dibutuhkan sebagai proses pembelajaran.

d. Guna penelitian berikutnya, diharapkan seorang peneliti mampu meningkatkan motivasi dalam hal kehadiran siswa di sekolah agar proses penelitian berjalan lancar sesuai dengan yang telah direncanakan.

\section{DAFTAR PUSTAKA}

Hernovan (2015), Perbandingan Model Pembelajaran NHT Dengan TPS Terhadap Aktivitas Dan Hasil Belajar Siswa. Artikel Fakultas Keguruan Dan Ilmu Pendidikan Universitas Lampung Bandar Lampung.

Murti, Redjeki, dan Utomo. 2014. Studi Komparasi Metode Pembelajaran Kooperatif Numbered Heads Together (NHT) Dan Think Pair Share (TPS) Dengan Memperhatikan Kemampuan Matematika Terhadap Prestasi Belajar Siswa Pada Materi Pokok Larutan Penyangga Di SMA Negeri 1 Jumapolo Tahun Pelajaran 2013/2014. Jurnal Pendidikan Kimia (JPK), Vol. 3 No. 4 Tahun 2014 Program Studi Pendidikan Kimia Universitas Sebelas Maret.

Rahmawati dan Mukminan. 2012. Pengaruh Model Pembelajaran Kooperatif TPS Dan NHT Terhadap Hasil Belajar Sejarah Di SMA Negeri Kabupaten Temanggung. Jurnal Pendidikan Ilmu Pengetahuan Sosial Program Pascasarjana Universitas Negeri Yogyakarta.

Sudarwati, Utami, Martini. 2014. Penerapan Metode Pembelajaran Numbered Heads Together (NHT) Untuk Meningkatkan Motivasi Dan Hasil Belajar Kelarutan Dan Hasil Kali Kelarutan Kelas XI IPA 4 SMAN 8 Surakarta Tahun Pelajaran 2012/2013. Jurnal Pendidikan Kimia (JPK), Vol. 3 No. 2 Tahun 2014 Program Studi Pendidikan Kimia Universitas Sebelas Maret 